\title{
AN INFLUENCE OF PARAMETERS OF MICRO-ELECTRICAL DISCHARGE MACHINING ON WEAR OF TOOL ELECTRODE
}

\begin{abstract}
To achieve better precision of features generated using the micro-electrical discharge machining (micro-EDM), there is a necessity to minimize the wear of the tool electrode, because a change in the dimensions of the electrode is reflected directly or indirectly on the feature. This paper presents a novel modeling and analysis approach of the tool wear in micro-EDM using a systematic statistical method exemplifying the influences of capacitance, feed rate and voltage on the tool wear ratio. The association between tool wear ratio and the input factors is comprehended by using main effect plots, interaction effects and regression analysis. A maximum variation of four-fold in the tool wear ratio have been observed which indicated that the tool wear ratio varies significantly over the trials. As the capacitance increases from 1 to $10 \mathrm{nF}$, the increase in tool wear ratio is by $33 \%$. An increase in voltage as well as capacitance would lead to an increase in the number of charged particles, the number of collisions among them, which further enhances the transfer of the proportion of heat energy to the tool surface. Furthermore, to model the tool wear phenomenon, a regression relationship between tool wear ratio and the process inputs has been developed.
\end{abstract}

\section{Introduction}

Electrical discharge machining has been a highly effective technique for machining complex features on electrically conductive materials, irrespective of other physical and mechanical properties. In the past, many researchers have attempted to machine different kinds of 'difficult-to-cut' materials using spark machining-based technologies [1-9]. The endeavors primarily involved optimization of the processing conditions in macro electrical discharge machining [1, 4-7], micro-electrical discharge machining [2], green electrical discharge machining [3] and other hybrid processes using the spark machining principles [8,9]. A few researchers [10-12]

\footnotetext{
${ }^{1}$ Post-doctoral researcher, Technical University of Denmark, Lyngby, Denmark - 2800. Email: gput.at.mek.dtu.dk@gmail.com
} 
have focused their attention on using alternate methods for increasing the material removal rate through chemical and mechanical actions using application of powders or surfactants. In this regard, effect of graphite powder and surfactants have been discussed in [10]. The performance outputs such as material removal rate and surface roughness have been investigated in [11]. The effect of using silicon, graphite and tungsten powder on the material migration was characterized and analyzed in detail [12].

The micro-electrical discharge machining (micro-EDM) is a novel technique for machining precise three-dimensional features of dimensions between 1 and 500 $\mu \mathrm{m}$. In most of the recent investigations, the process characteristics and capabilities of micro-EDM have been studied and applied for several industrial applications [13-32]. The stainless steels are characterized by the inherent luster, high corrosion resistance, strength, and therefore adequate attention has been allocated to the micro-EDM investigations on these class of materials [13-20]. Jahan et. al. [13] has studied the capability of cemented carbide (WC-Co) against austenitic stainless steel (SUS 304) with a focus on processing conditions and material removal mechanism. Generation of high aspect ratio micro-holes has always been a pronounced research issue in micro-EDM, and has been addressed to some extent in [14]. The appropriate choice of pulse generators and process control strategies $[15,17]$ has gained importance recently. In addition, the micro-EDM process applied to finish machining process conditions and rough machining conditions has helped to identify the best parametric requirements [16, 18-20]. The effect of process parameters on finish machining in micro-EDM has been studied in [18]. Wong et al. [19] has undertaken the analysis of single discharge micro-EDM for deep understanding of the process mechanism.

The unique capabilities of micro-EDM-based processes and the correlation between the process performance outputs and the input process settings has been explored in detail by many researchers [21-32]. Kim et. al. [21] has developed a novel micro-EDM hybridized with ultrasonic vibrations for machining of a straight hole with a cylindrical tool electrode using a variable capacitance method. A newly established micro-feed mechanism have been successfully employed for material removal using the micro-EDM process [22]. The micro-EDM plasma characteristics have been studied using optical spectroscopy methods [23]. The optimization of micro-EDM process parameters at various processing conditions was analyzed and compared [24, 25] and for 'difficult-to-machine' materials as well [26]. The possibility of drilling on a high-nickel alloy using micro-EDM have been examined in [27]. The results of this study revealed the favorable process parameters; discharge current of $500 \mathrm{~mA}$ and a pulse duration of $4 \mu \mathrm{s}$, yielding the highest material removal rate and minimum tool wear rate. Furthermore, Amorim et al. [28] have analyzed the effect of generator actuation modes and micro-EDM controllable factors on the quality of machined surfaces. Natarajan et al. [29] has carried out a detailed micro-ED hole drilling experimentation to evaluate the surface roughness, material removal rate and tool wear ratio. The optimum 
parametric conditions were identified and the optimum values of material removal rate, tool wear ratio and surface roughness of $0.019 \mathrm{~mm}^{3} / \mathrm{min}, 0.52 \mu \mathrm{m}$ and 1.18 were respectively obtained.

The micro-EDM research works have shown that the tool electrode wear is one of the key issues during the machining, which directly reflects on the accuracy of the machined features. Therefore, in order to resist quick consumption of the tool electrodes, a few researchers have attempted to fabricate electrodes using advanced techniques such as electrochemical deposition and multi-EDM grinding, however, were effective only to some extent [30,31]. Furthermore, LIGA technique and micro-EDM techniques were combined aiming at generation of high aspect ratio micro-features [32]. It is based on conception elaborated by authors of the paper [29].

Micro-EDM drilling has been recognized as the most suitable technique for effectual generation of high aspect ratio micro-holes. One of the recent studies [29] have demonstrated the capabilities of the process and evaluated the process outputs, however, the research issue concerning tool electrode wear remains unsolved. Therefore, the objective of this paper is to present an altered discussion on the results of tool wear ratio through a systematic modeling and analysis approach. Statistical tools have been used to develop a correlation between the tool wear ratio and the input parameters. Furthermore, two-dimensional individual parameter plots have been developed to understand the parameter effects on the tool wear ratio.

\section{Methodology}

The methodology for modeling the micro-EDM process for prediction of the tool electrode wear is shown in Fig. 1a. As can be seen, the feed rate, capacitance and voltage controls the input to the process. The measurable outputs are further construed as a single process response in terms of the tool electrode wear ratio. The stages and parameters of the experiments are presented in Fig. $1 b$.

This work involves process-modeling attempts to generate a correlation between the tool wear ratio and the inputs to the micro-EDM process. The techniques employed in this investigation are: i) main effects plots, ii) interaction plots, and iii) regression analysis. As far as the tool wear ratio is concerned, the magnitudes were more than zero, indicating that the tool electrode wear was positive in the microEDM process in all the experiments conducted. The variations in the magnitudes of tool wear ratio are graphically represented in section 3 .

\section{Tool wear ratio}

To improve the accuracy of the micro-EDM process at various processing conditions, a control of the magnitude of the tool electrode wear is necessary based on a response variable named as 'tool wear ratio'. Tool wear ratio is defined as the 


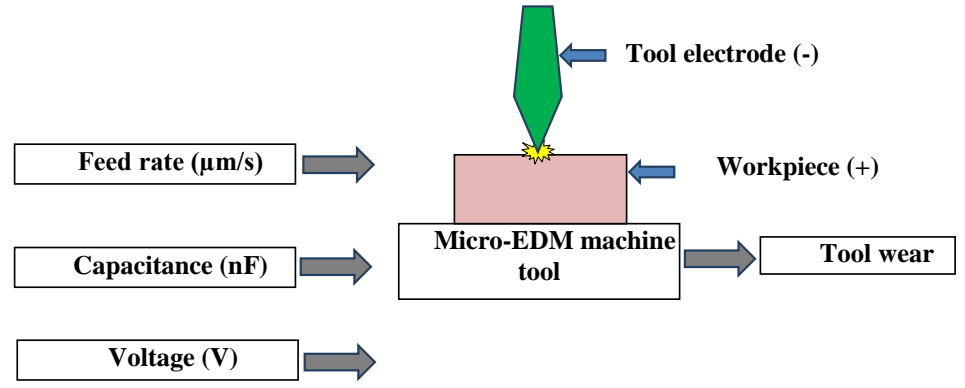

a)

\begin{tabular}{|l|c|c|c|}
\hline \multirow{2}{*}{ Parameters } & \multicolumn{3}{|c|}{ Stages } \\
\cline { 2 - 4 } & 1 & 2 & 3 \\
\hline Feed rate $(\mu \mathrm{m} / \mathrm{s})$ & 2 & 4 & 6 \\
\hline Capacitance $(\mathrm{nF})$ & 0.1 & 1.0 & 10.0 \\
\hline Voltage $(\mathrm{V})$ & 80 & 100 & 120 \\
\hline
\end{tabular}

b)

Fig. 1. a) A schematic of the basic experimental set-up [29] for evaluating the effect of micro-EDM inputs illustrating the methodology, b) stages and parameters of the experiments

ratio of tool wear rate to the material removal rate for the current tool-workpiece combination at all processing conditions for the current micro-EDM configuration, mathematically expressed as

$$
\text { Tool wear ratio }=\mathrm{TWR} / \mathrm{MRR} \text {, }
$$

where

$$
\text { TWR }=\text { Volume of tool electrode wear/Machining time }
$$

and

$$
\mathrm{MRR}=\text { Volume of removed material/Machining time } .
$$

The magnitudes of the tool wear ratios for all the trials is presented in Fig. 2. The average tool wear ratio is calculated as 1.97 for the entire trails presented here. The maximum tool wear ratio corresponds to trial \#25 as 3.16 and the minimum is 0.54 at trial \#2. Therefore, a maximum variation of four-fold in the tool wear ratio could be observed. This indicates that the tool wear ratio varies significantly over the trials and therefore, a thorough analysis is necessary by taking into account the effect of each input parameter independently. Nevertheless, from the trends in the plot shown here, it can be observed that an increasing trend occurs between trial \#3 and trial \#27. Furthermore, after trial \#28, for the remaining trials, the tool wear ratio decreases sharply. 


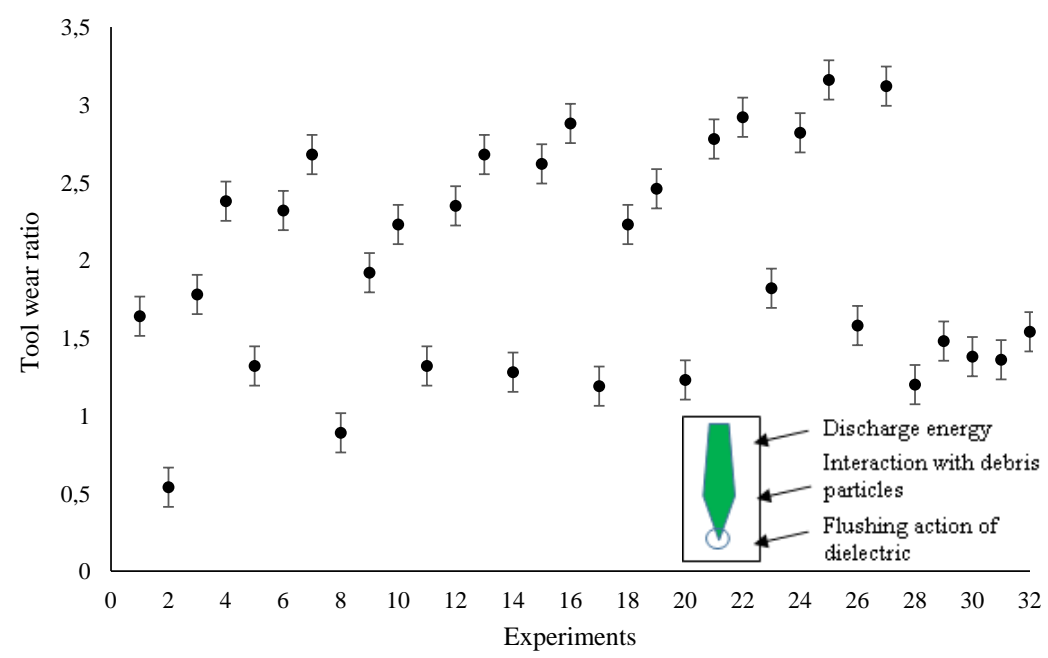

Fig. 2. The data of tool electrode wear ratio for all the experimental trials and an illustration of the causes of tool wear in the micro-EDM process

\section{Variations of the tool wear ratio}

The analysis of the tool wear ratio involves the main effects as well as the interaction effects on the tool electrode wear ratio. The main effect plots represent the individual and straight effect of the inputs on the tool wear ratio, whereas the interaction plots show the combined effects of the inputs on the tool wear ratio. The magnitude of tool wear ratios presented here are the calculated means or averages of tool wear ratios at various levels of the input parameters, viz. feed rate, capacitance and voltage. Fig. 3a-c shows the main effect plots for tool wear ratio, with the mean or average along the ordinate and the parameters along the abscissa. The capacitance and voltage follows increasing trends. The plots indicate that these two factor significantly control the tool wear ratio in the micro-EDM drilling process and influences the tool wear mechanisms.

The trend of variation of the tool wear ratio with the capacitance is observed to be in an increasing way. The plot between tool wear ratio and the capacitance is presented in Fig. 3b. As the capacitance increases from 0.1 to $1 \mathrm{nF}$, the increase in tool wear ratio is by $6 \%$. It is known that an increase in the capacitance causes an increase in the discharge energy and consequently, a proportional increase in the heat energy transferred to the tool electrode. Further, the capacitance increases by 10 times to $10 \mathrm{nF}$. As a result, the increase in tool wear ratio is by $33 \%$, i.e. 5 times the increase observed earlier. This phenomenon could be attributed to the particularities of the charging and discharging of the capacitor in the case of a micro-EDM process. A similar effect of diverse effect of capacitance of the circuit as well as the stray capacitance on the tool wear ratio has been evident in [33]. Therefore, under normal micro-EDM process conditions, an overall increase in 


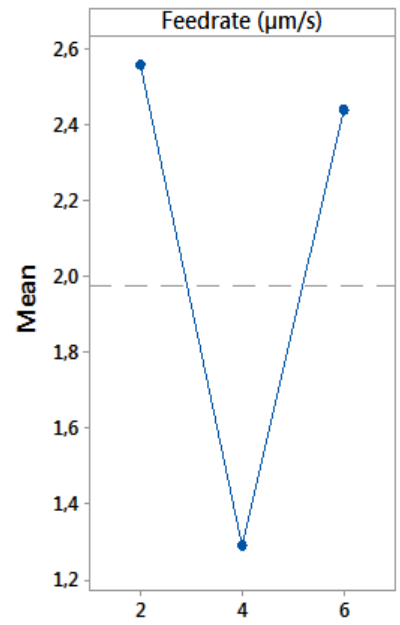

(a)

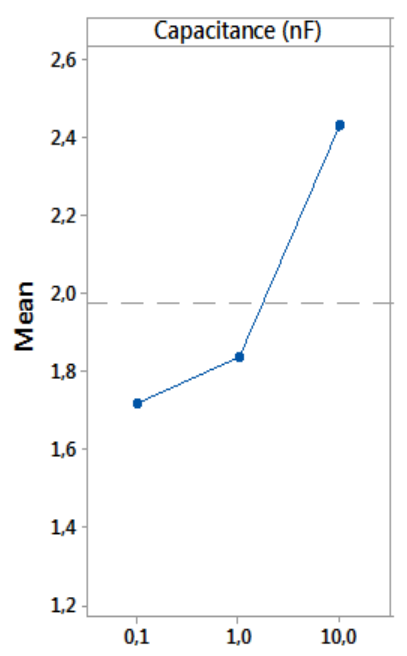

(b)

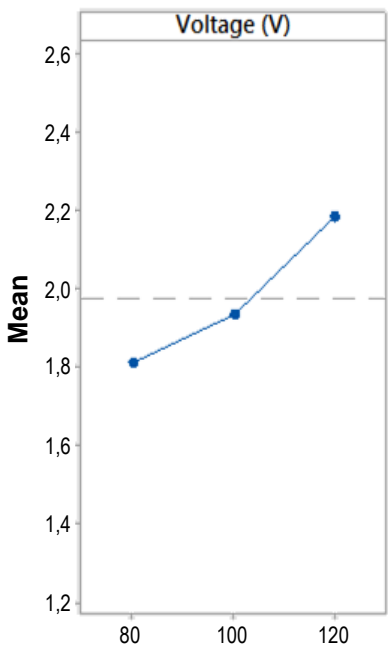

(c)

Fig. 3. Main effects plot for tool wear ratio with: a) feed rate, b) capacitance and c) voltage

discharge energy, and consequently the tool wear ratio has been proven. Through a capacitor, charge flows, as mathematically represented by:

$$
Q=C \cdot V \text {. }
$$

Differentiating on both sides

$$
\frac{\mathrm{d} Q}{\mathrm{~d} t}=C \frac{\mathrm{d} V}{\mathrm{~d} t} .
$$

Therefore, discharge current $I$ is obtained as

$$
I=\frac{\mathrm{d} Q}{\mathrm{~d} t}=C \frac{\mathrm{d} V}{\mathrm{~d} t} .
$$

The discharge energy $E$ causing material removal from the tool electrode surface in the micro-EDM process is obtained as

$$
E=\frac{1}{2} C V^{2} .
$$

Thus, the discharge energy $E$ increases directly with the capacitance and with the square of the voltage. The effect of an increase in capacitance is to enhance the number of charged particles travelling towards the cathode in the micro-EDM plasma, and is schematically illustrated in Fig. 4. An increase in the number of charged particles increases the number of collisions, which further enhances the transfer of the proportion of heat energy to the cathode [34].

The analysis of means plot presented in Fig. $3 c$ shows a linear increase in tool wear ratio with voltage. The overall increase in tool wear ratio has been $22 \%$. 


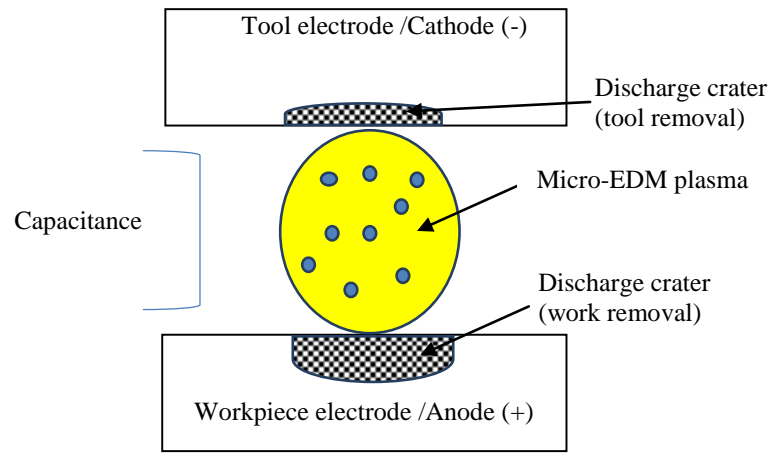

Fig. 4. Effect of capacitance on the micro-EDM discharge plasma

A similar effect was evident in the macro EDM process with the aid of vibrations [33]. As the voltage increases from 80 to $100 \mathrm{~V}$, the tool wear ratio increases by $10 \%$.A further increase in voltage from 100 to $120 \mathrm{~V}$ causes an increase in tool wear ratio by $12 \%$. This clearly indicating that though voltage has a favorable effect on the material removal rate, at the same time; it adversely affects the consumption of the tool electrode. The discharge energy in the case of micro-EDM process varies as the square of the discharge voltage [19], and as a result, the tool wear ratio increases, see eq. (4) for explanation.

A plot of the effect of feed rate on the tool wear ratio is shown in Fig. 3a. The lowest tool wear ratio can be seen at a feed rate of $4 \mu \mathrm{m} / \mathrm{s}$. However, an overall decrease in the tool wear ratio is observed with feed rate in this study. This indicates that the tool wear ratio could be affected by the rate of material removal during the micro-EDM drilling process. The normal probability plot, residual plot and histogram for the trials of tool wear ratio is presented in Fig. 5.

\section{Effect of parametric interactions on wear of tool electrode}

The interaction plots of the effects of the three significant interactions: feed rate $\times$ capacitance; voltage $\times$ capacitance and feed rate $\times$ voltage are presented in Fig. 6.

The results of interaction effects on the tool wear ratio indicate that when feed rate and capacitance interact, a maximum increase in tool wear ratio of $200 \%$ is observed, which is critical for micro-EDM operation. The increase of tool wear ratio was evident at all levels of the capacitance and a feed rate of $6 \mu \mathrm{m} / \mathrm{s}$. The increase in feed rate may affect the stability of the micro-EDM plasma, than might have caused a higher transfer of discharge energy to the cathode (tool electrode). The results of the effects of feed rate $\times$ capacitance interaction is presented in Fig. 6, and summarized in Table 1.

Similarly, the individual effect of the voltage is to increase the tool wear rate, however, for interaction feed rate $\times$ voltage, at feed rate of $4 \mu \mathrm{m} / \mathrm{s}$ and for all 

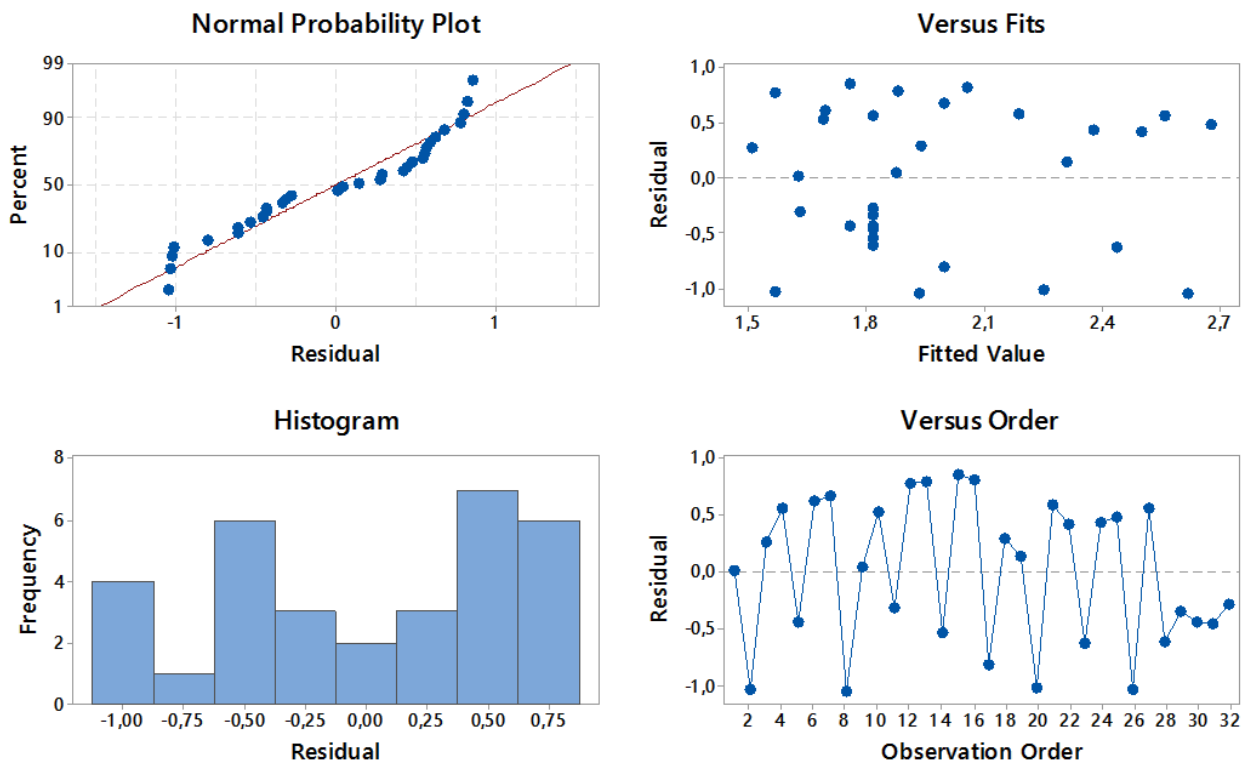

Fig. 5. The normal probability plot, residual plot, histogram and observation plot for tool wear ratio

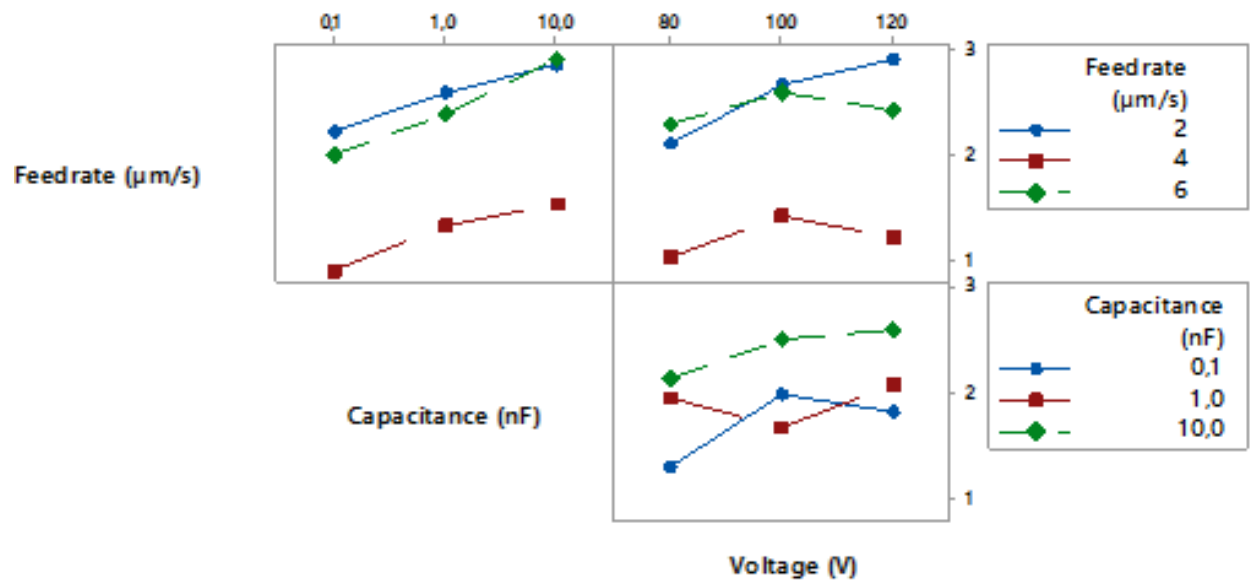

Fig. 6. Interaction effects on the tool wear ratio (interactions: feed rate $\times$ capacitance, voltage $x$ capacitance and feed rate $\times$ voltage)

the levels of voltage, a decrease in the tool wear ratio is observed. A decrease in discharge energy at higher voltages has been observed earlier in the macro EDM investigations [35-37]. Therefore, in the micro-EDM, a lower tool electrode wear ratio could be achieved at higher magnitude of voltages in combination with feed rates. A summary of the interaction effects is presented in Table 2 .

The effect of the voltage $\times$ capacitance interaction on the tool wear ratio is shown in Fig. 5 and summarized in Table 3. As can be observed from Fig. 5, the 
Table 1

A summary of the results of feed rate $\times$ capacitance interaction

\begin{tabular}{|c|c|c|c|c|}
\hline \multicolumn{5}{|c|}{ Interaction: feed rate $\times$ capacitance on tool wear ratio } \\
\hline \multirow{2}{*}{$\begin{array}{c}\text { Capacitance } \\
(\mathrm{nF})\end{array}$} & \multicolumn{3}{|c|}{ Feed rate $(\mu \mathrm{m} / \mathrm{s})$} & \multirow{2}{*}{ Inferences } \\
\hline & 2 & 4 & 6 & \\
\hline 0.1 & - & $79 \%$ decrease & $200 \%$ increase & \multirow{3}{*}{$\begin{array}{l}\text { Between }(1 \mathrm{nF}, 2 \mu \mathrm{m} / \mathrm{s}) \text { and }(10 \mathrm{nF} \text {, } \\
2 \mu \mathrm{m} / \mathrm{s}) \text {, smallest increase in tool } \\
\text { wear ratio is observed. The largest } \\
\text { decrease in tool wear ratio of } 79 \% \\
\text { is obtained at }(0.1 \mathrm{nF}, 4 \mu \mathrm{m} / \mathrm{s}) .\end{array}$} \\
\hline 1.0 & $16 \%$ increase & $50 \%$ decrease & $66 \%$ increase & \\
\hline 10.0 & $7 \%$ increase & $46 \%$ decrease & $100 \%$ increase & \\
\hline
\end{tabular}

Table 2.

A summary of the results of feed rate $\times$ voltage interaction

\begin{tabular}{|c|c|c|c|c|}
\hline \multicolumn{5}{|c|}{ Interaction: feed rate $\times$ voltage on tool wear ratio } \\
\hline \multirow{2}{*}{$\begin{array}{l}\text { Voltage } \\
\text { (V) }\end{array}$} & \multicolumn{3}{|c|}{ Feed rate $(\mu \mathrm{m} / \mathrm{s})$} & \multirow{2}{*}{ Inferences } \\
\hline & 2 & 4 & 6 & \\
\hline 80 & - & $54 \%$ decrease & $150 \%$ increase & \multirow{3}{*}{$\begin{array}{l}\text { The smallest increase in tool wear } \\
\text { ratio is observed between }(2 \mu \mathrm{m} / \mathrm{s} \text {, } \\
100 \mathrm{~V}) \text { and }(2 \mu \mathrm{m} / \mathrm{s}, 120 \mathrm{~V}) \text {. }\end{array}$} \\
\hline 100 & $23 \%$ increase & $44 \%$ decrease & $66 \%$ increase & \\
\hline 120 & $11 \%$ increase & $56 \%$ decrease & $100 \%$ increase & \\
\hline
\end{tabular}

effect of voltage and capacitance on the discharge energy is reflected on the tool wear ratio. Therefore, at $(80 \mathrm{~V}, 0.1 \mathrm{nF}),(100 \mathrm{~V}, 1.0 \mathrm{nF})$ and $(120 \mathrm{~V}, 10.0 \mathrm{nF})$, the predominant effect is to linearly increase the tool wear ratio. This is in accordance with the physical phenomenon mathematically exemplified in eq. (4). Moreover, the effect of this interaction is schematically presented in Fig. 7. An increase in tool electrode wear ratio could be due to an enhanced ionization and mobility of the charged particles that causes an increase in the energy of sparks. As a result, an enlargement of each discharge crater by an increase in the diameter as well as depth, on the tool electrode surface would cause an overall increase in the tool wear ratio.

Table 3.

A summary of the results of capacitance $\times$ voltage interaction

\begin{tabular}{|c|c|c|c|l|}
\hline \multicolumn{5}{|c|}{ Interaction: capacitance $\times$ voltage on tool wear ratio } \\
\hline \multirow{2}{*}{$\begin{array}{c}\text { Voltage } \\
(\mathrm{V})\end{array}$} & \multicolumn{3}{|c|}{ Capacitance $(\mathrm{nF})$} & \multirow{2}{*}{ Inferences } \\
\cline { 2 - 4 } & 0.10 & 1.0 & 10.0 & \\
\hline 80 & - & $40 \%$ decrease & $15 \%$ increase & $\begin{array}{l}\text { The highest level of capacitances } \\
\text { causes increase in the tool wear } \\
\text { ratio irrespective of the level of } \\
\text { the voltage. }\end{array}$ \\
\hline 100 & $33 \%$ increase & $10 \%$ decrease & $50 \%$ increase \\
\hline 120 & $15 \%$ increase & $10 \%$ decrease & $38 \%$ increase & \\
\hline
\end{tabular}




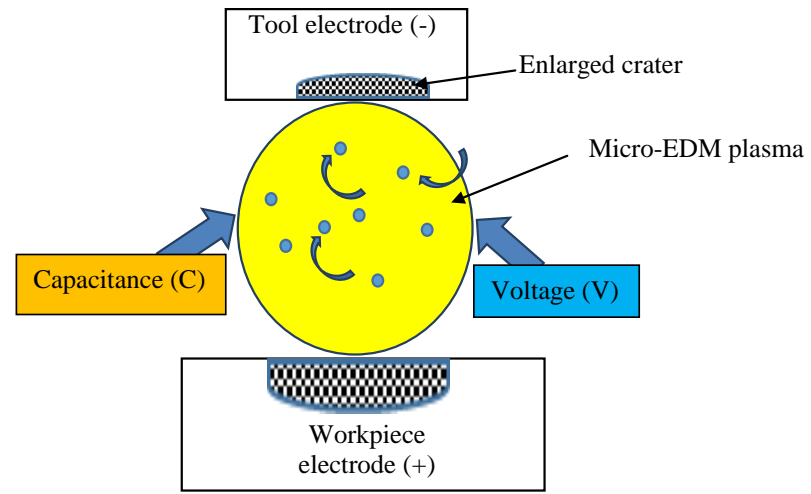

Fig. 7. A schematic illustration of the effect of capacitance $\times$ voltage interaction on the tool electrode wear ratio

\section{Regression analysis of tool wear ratio}

Regression analysis is a statistical modeling procedure for estimating the relationship among the variables governing a physical phenomenon [38]. In this micro-EDM investigation, tool wear ratio is the dependent variable; voltage, capacitance and feed rate are the independent variables. The regression relationship between tool wear ratio and the process inputs are therefore established, and the results are presented in Table 4.

Table 4.

Results of the regression analysis

\begin{tabular}{|c|c|c|c|c|c|c|}
\hline \multicolumn{7}{|c|}{ Regression coefficients } \\
\hline Term & Coefficient & SE coefficient & T-value & P-Value & TIF & Inferences \\
\hline Constant & 0.86 & 4.11 & 0.21 & 0.835 & 0 & \multirow{5}{*}{$\begin{array}{l}\text { Regression } \\
\text { constant is } 0.86, \\
\text { and therefore, } \\
\text { model is adequate. } \\
\text { Capacitance is the } \\
\text { most significant } \\
\text { input factor. }\end{array}$} \\
\hline Feed rate $(\mu \mathrm{m} / \mathrm{s})$ & -0.0303 & 0.0800 & -0.38 & 0.708 & 1.00 & \\
\hline Capacitance (nF) & 0.0691 & 0.0286 & 2.41 & 0.023 & 1.01 & \\
\hline Voltage (V) & 0.0104 & 0.0622 & 0.17 & 0.868 & 60.44 & \\
\hline $\begin{array}{l}\text { Voltage } \times \text { voltage } \\
\times \text { voltage }\end{array}$ & 0 & 0.000002 & -0.02 & 0.984 & 60.45 & \\
\hline
\end{tabular}

In the regression model, the contributing factors for prediction of the tool wear ratio (TWR) are the parameters feed rate, capacitance, voltage and an interaction voltage ${ }^{3}$. The other two-factor and three-factor interactions associated with the current micro-EDM process those are assumed to influence the process are found to have no significant effect in prediction of the tool wear ratio in the model.

The regression constant of 0.86 shows that the model is adequate enough to make further predictions on the tool electrode wear ratio with capacitance, feed 
rate and voltage. The capacitance has been observed to be significantly influencing the tool wear ratio at all the levels and other processing conditions.

Based on the regression analysis, input-output relationship has been obtained in coded units. The mathematical expression is:

$$
\begin{gathered}
\text { Tool wear ratio }(\text { TWR })=0.86-0.0303 \times \text { Feed rate }(\mu \mathrm{m} / \mathrm{s})+ \\
+0.0691 \times \text { Capacitance }(\mathrm{nF})+0.0104 \times \text { Voltage }(\mathrm{V}) .
\end{gathered}
$$

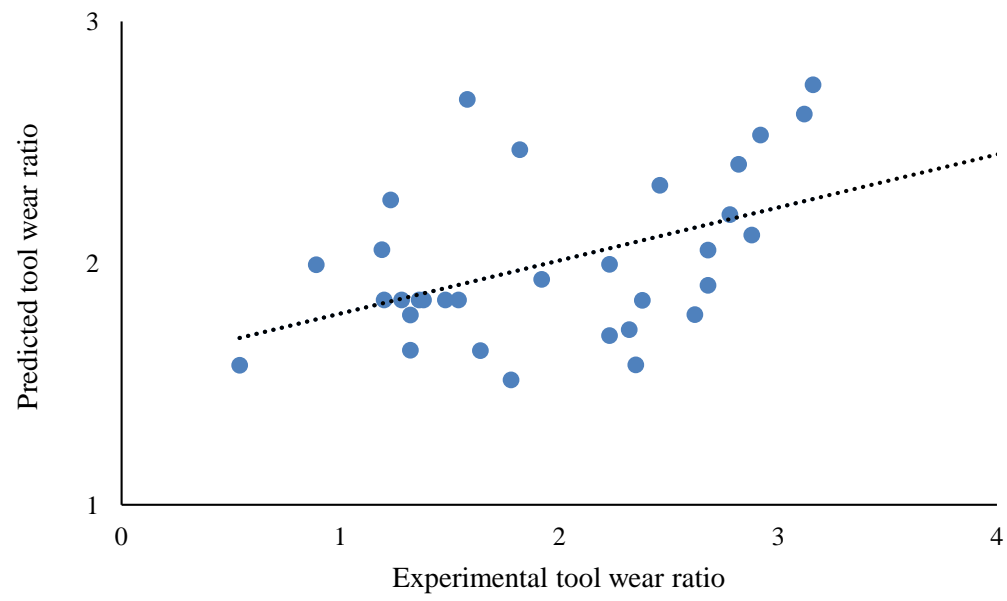

Fig. 8. Graph representing the relationship between predicted tool wear ratio and experiemntal tool wear ratio

Fig. 8 shows a plot between the calculated values of the tool wear ratio based on the regression analysis and the experimentally observed tool wear ratio.

\section{Conclusions}

This paper investigates the effect of feed rate, capacitance and voltage on the wear characteristics of the tool electrode in micro electrical discharge machining through a combined analysis and modeling approach, focusing on the influence of the parameters. The analysis involved the effects of micro-EDM parameters on variations in the magnitude of tool electrode wear ratio. The effect of each individual input factor on the tool wear ratio have been independently analyzed. The plausible causes for a significant increase or decrease in the tool wear ratio have been explained using the physics of the process. The explicit conclusions of this work are enumerated as follows:

- A systematic modeling and analysis approach have been used to study the tool electrode wear phenomenon in the micro-EDM process. Statistical tools involving main effects plots, interaction plots and regression analysis are used 
to examine the data and to develop the process input-output relationships. In the data, maximum tool wear ratio corresponds to trial \#25 as 3.16 and the minimum is 0.54 at trial \#2.

- Main effects plots based on analysis of means are used to investigate the independent effects of capacitance, voltage and feed rate on the tool electrode wear ratio. As the parameter capacitance increases from 0.1 to $1 \mathrm{nF}$, the increase in tool wear ratio is by $6 \%$. Further, the capacitance increases by 10 times to $10 \mathrm{nF}$. As a result, the increase in tool wear ratio is by $33 \%$, i.e., 5 times the increase observed earlier. This effect could be attributed to the particularities of the charging and discharging of the capacitor in the case of a micro-EDM process for the current configuration.

- As the voltage increases from 80 to $100 \mathrm{~V}$, the tool wear ratio increases by $10 \%$. A further increase in voltage from 100 to $120 \mathrm{~V}$ causes a higher increase in tool wear ratio by $12 \%$. This clearly indicates that though voltage has a favorable effect on the material removal rate, at the same time; it adversely affects the consumption of the tool electrode. The effect could be attributed to an increase in discharge gap at higher voltages, to maintain the minimum electric field necessary to initiate a discharge.

- The results of interaction effects on the tool wear ratio indicate that when feed rate and capacitance interact, a maximum increase in tool wear ratio of $200 \%$ is observed, and the variation is critical for micro-EDM operation. Thus, it is evident that even a small fluctuation in the feed rate controls the capacitance charging and discharge phenomena in the micro-EDM process. The individual effect of the voltage is to increase the tool wear rate, however, for interaction feed rate $\times$ voltage, at feed rate of $4 \mu \mathrm{m} / \mathrm{s}$ and for all the levels of voltage, a decrease in the tool wear ratio is observed.

- A regression relationship between tool wear ratio and the process inputs have been established. The regression constant of 0.86 shows that the model is adequate enough to make further predictions on the tool electrode wear ratio with capacitance, feed rate and voltage. The capacitance has been observed to be significantly influencing the tool wear ratio at all the levels and other processing conditions. A plot between predicted tool wear ratio and actual tool wear ratio has been developed.

\section{Acknowledgements}

The research leading to these results has received funding from the People Programme (Marie Curie Actions) of the European Union Seventh Framework Programme (FP7/2007-2013) under COFUNDPostdocDTU. 


\section{References}

[1] L. Tang and Y.F. Guo. Electrical discharge precision machining parameters optimization investigation on S-03 special stainless steel. The International Journal of Advanced Manufacturing Technology, 70(5-8):1369-1376, 2014. doi: 10.1007/s00170-013-5380-4.

[2] V.K. Meena and M.S. Azad. Grey relational analysis of micro-EDM machining of Ti-6Al-4V alloy. Materials and Manufacturing Processes, 27(9):973-977, 2012. doi: 10.1080/10426914.2011.610080.

[3] S.P. Sivapirakasam, J. Mathew, and M. Surianarayanan. Multi-attribute decision making for green electrical discharge machining. Expert Systems with Applications, 38(7):8370-8374, 2011. doi: 10.1016/j.eswa.2011.01.026.

[4] T. Muthuramalingam and B. Mohan. Influence of discharge current pulse on machinability in electrical discharge machining. Materials and Manufacturing Processes, 28(4):375-380, 2013. doi: 10.1080/10426914.2012.746700.

[5] Y.H. Guu, C.Y. Chou, and S.-T. Chiou. Study of the effect of machining parameters on the machining characteristics in electrical discharge machining of Fe-Mn-Al alloy. Materials and Manufacturing Processes, 20(6):905-916, 2005. doi: 10.1081/AMP-200060412.

[6] B. Jabbaripour, M.H. Sadeghi, Sh. Faridvand, and M.R. Shabgard. Investigating the effects of EDM parameters on surface integrity, MRR and TWR in machining of Ti-6Al-4V. Machining Science and Technology, 16(3):419-444, 2012.

[7] R. Mukherjee and S. Chakraborty. Selection of EDM process parameters using biogeographybased optimization algorithm. Materials and Manufacturing Processes, 27(9):954-962, 2012. doi: 10.1080/10426914.2011.610089.

[8] S.S. Agrawal and V. Yadava. Modeling and prediction of material removal rate and surface roughness in surface-electrical discharge diamond grinding process of metal matrix composites. Materials and Manufacturing Processes, 28(4):381-389, 2013. doi: 10.1080/10426914.2013.763678.

[9] M.Ch. Panda and V. Yadava. Intelligent modeling and multiobjective optimization of die sinking electrochemical spark machining process. Materials and Manufacturing Processes, 27(1):10-25, 2012. doi: 10.1080/10426914.2010.544812.

[10] V.V. Reddy, A. Kumar, P.M. Valli, and C.S. Reddy. Influence of surfactant and graphite powder concentration on electrical discharge machining of PH17-4 stainless steel. Journal of the Brazilian Society of Mechanical Sciences and Engineering, 37(2):641-655, 2015. doi: 10.1007/s40430-014-0193-4.

[11] B. Jabbaripour, M.H. Sadeghi, M.R. Shabgard, and H. Faraji. Investigating surface roughness, material removal rate and corrosion resistance in PMEDM of $\gamma$-TiAl intermetallic. Journal of Manufacturing Processes, 15(1):56-68, 2013. doi: 10.1016/j.jmapro.2012.09.016.

[12] A. Bhattacharya, A. Batish, and N. Kumar. Surface characterization and material migration during surface modification of die steels with silicon, graphite and tungsten powder in EDM process. Journal of Mechanical Science and Technology, 27(1):133-140, 2013. doi: 10.1007/s12206-012-0883-8.

[13] M.P. Jahan, Y.S. Wong, and M. Rahman. A comparative experimental investigation of deep-hole micro-EDM drilling capability for cemented carbide (WC-Co) against austenitic stainless steel (SUS 304). The International Journal of Advanced Manufacturing Technology, 46(9-12):11451160, 2010. doi: 10.1007/s00170-009-2167-8.

[14] H.S. Lim, Y.S. Wong, M. Rahman, and M.K.E. Lee. A study on the machining of highaspect ratio micro-structures using micro-EDM. Journal of Materials Processing Technology, 140(1):318-325, 2003. doi: 10.1016/S0924-0136(03)00760-X. 
[15] M.P. Jahan, Y.S. Wong, and M. Rahman. A comparative study of transistor and RC pulse generators for micro-EDM of tungsten carbide. International Journal of Precision Engineering and Manufacturing, 9(4):3-10, 2008.

[16] H.S. Liu, B.H. Yan, F.Y. Huang, and K.H. Qiu. A study on the characterization of high nickel alloy micro-holes using micro-EDM and their applications. Journal of Materials Processing Technology, 169(3):418-426, 2005. doi: 10.1016/j.jmatprotec.2005.04.084.

[17] F. Han, S. Wachi, and M. Kunieda. Improvement of machining characteristics of microEDM using transistor type isopulse generator and servo feed control. Precision Engineering, 28(4):378-385, 2004. doi: 10.1016/j.precisioneng.2003.11.005.

[18] F.L. Amorim and W.L. Weingaertner. The influence of generator actuation mode and process parameters on the performance of finish EDM of a tool steel. Journal of Materials Processing Technology, 166(3):411-416, 2005. doi: 10.1016/j.jmatprotec.2004.08.026.

[19] Y.S. Wong, M. Rahman, H.S. Lim, H. Han, and N. Ravi. Investigation of micro-EDM material removal characteristics using single RC-pulse discharges. Journal of Materials Processing Technology, 140(1):303-307, 2003. doi: 10.1016/S0924-0136(03)00771-4.

[20] N. Natarajan and P. Suresh. Experimental investigations on the microhole machining of 304 stainless steel by micro-EDM process using RC-type pulse generator. The International Journal of Advanced Manufacturing Technology, 77(9-12):1741-1750, 2015. doi: 10.1007/s00170-0146494-z.

[21] D.J. Kim, S.M. Yi, Y.S. Lee, and C.N. Chu. Straight hole micro EDM with a cylindrical tool using a variable capacitance method accompanied by ultrasonic vibration. Journal of Micromechanics and Microengineering, 16(5):1092, 2006. http://stacks.iop.org/0960$1317 / 16 / \mathrm{i}=5 / \mathrm{a}=031$.

[22] Y. Li, M. Guo, Z. Zhou, and M. Hu. Micro electro discharge machine with an inchworm type of micro feed mechanism. Precision Engineering, 26(1):7-14, 2002. doi: 10.1016/S01416359(01)00088-5.

[23] J. Ramkumar, N. Glumac, S.G. Kapoor, and R.E. DeVor. Characterization of plasma in microEDM discharge using optical spectroscopy. Journal of Manufacturing Processes, 11(2):82-87, 2009. doi: 10.1016/j.jmapro.2009.10.002.

[24] K.P. Maity and R.K. Singh. An optimisation of micro-EDM operation for fabrication of microhole. The International Journal of Advanced Manufacturing Technology, pages 1-9, 2012. doi: 10.1007/s00170-012-4098-z.

[25] M.S. Azad and A.B. Puri. Simultaneous optimisation of multiple performance characteristics in micro-EDM drilling of titanium alloy. The International Journal of Advanced Manufacturing Technology, 61(9-12):1231-1239, 2012. doi: 10.1007/s00170-012-4099-y.

[26] B.B. Pradhan, M. Masanta, B.R. Sarkar, and B. Bhattacharyya. Investigation of electro-discharge micro-machining of titanium super alloy. The International Journal of Advanced Manufacturing Technology, 41(11-12):1094, 2009. doi: 10.1007/s00170-008-1561-y.

[27] H.S. Liu, B.H. Yan, F.Y. Huang, and K.H. Qiu. A study on the characterization of high nickel alloy micro-holes using micro-EDM and their applications. Journal of Materials Processing Technology, 169(3):418-426, 2005. doi: 10.1016/j.jmatprotec.2005.04.084.

[28] F.L. Amorim and W.L. Weingaertner. The influence of generator actuation mode and process parameters on the performance of finish EDM of a tool steel. Journal of Materials Processing Technology, 166(3):411-416, 2005. doi: 10.1016/j.jmatprotec.2004.08.026.

[29] U. Natarajan, X.H. Suganthi, and P.R. Periyanan. Modeling and multiresponse optimization of quality characteristics for the micro-EDM drilling process. Transactions of the Indian Institute of Metals, 69(9):1675-1686, 2016. doi: 10.1007/s12666-016-0828-5. 
[30] M.A.Ahsan Habib and M. Rahman. Performance analysis of EDM electrode fabricated by localized electrochemical deposition for micro-machining of stainless steel. The International Journal of Advanced Manufacturing Technology, 49(9-12):975-986, 2010. doi: 10.1007/s00170009-2479-8.

[31] F.T. Weng, R.F. Shyu, and C.S. Hsu. Fabrication of micro-electrodes by multi-EDM grinding process. Journal of Materials Processing Technology, 140(1):332-334, 2003. doi: 10.1016/S0924-0136(03)00748-9.

[32] K. Takahata, N. Shibaike, and H. Guckel. High-aspect-ratio WC-Co microstructure produced by the combination of LIGA and micro-EDM. Microsystem Technologies, 6(5):175-178, 2000. doi: $10.1007 / \mathrm{s} 005420000052$.

[33] T.Y. Tai, T. Masusawa, and H.T. Lee. Drilling microholes in hot tool steel by using microelectro discharge machining. Materials Transactions, 48(2):205-210, 2007. doi: 10.2320/matertrans.48.205.

[34] D.D. DiBitonto, P.T. Eubank, M.R. Patel, and M.A. Barrufet. Theoretical models of the electrical discharge machining process. I. A simple cathode erosion model. Journal of Applied Physics, 66(9):4095-4103, 1989. doi: 10.1063/1.343994.

[35] P. Govindan and S.S. Joshi. Experimental characterization of material removal in dry electrical discharge drilling. International Journal of Machine Tools and Manufacture, 50(5):431-443, 2010. doi: 10.1016/j.ijmachtools.2010.02.004.

[36] S. Joshi, P. Govindan, A. Malshe, and K. Rajurkar. Experimental characterization of dry EDM performed in a pulsating magnetic field. CIRP Annals-Manufacturing Technology, 60(1):239242, 2011. doi: 10.1016/j.cirp.2011.03.114.

[37] P. Govindan, A. Gupta, S.S. Joshi, A. Malshe, and K.P. Rajurkar. Single-spark analysis of removal phenomenon in magnetic field assisted dry EDM. Journal of Materials Processing Technology, 213(7):1048-1058, 2013. doi: 10.1016/j.jmatprotec.2013.01.016.

[38] D.C. Montgomery. Design and Analysis of Experiments. John Wiley \& Sons, New York, 2008. 